\title{
Erratum
}

Journal of Microbiology (2014) Vol. 52, No. 2, pp. 169-178

DOI $10.1007 / \mathrm{s} 12275-014-3045-0$

Copyright (C) 2014, The Microbiological Society of Korea

\section{Predictive Modelling of Lactobacillus casei KN291 Survival in Fermented Soy Beverage}

\author{
Zielińska Dorota $^{1 \star}$, Kołożyn-Krajewska Danuta ${ }^{1}$, \\ Goryl Antoni ${ }^{2}$, and Ilona Motyl ${ }^{3}$
}

\author{
${ }^{1}$ Department of Food Gastronomy and Food Hygiene, Faculty of Human Nutrition and Consumer Sciences, \\ Warsaw University of Life Sciences -SGGW, ul. Nowoursynowska 159c, 02-776 Warsaw, Poland \\ ${ }^{2}$ Department of Econometrics and Operational Research, Cracow University of Economics ul. Rakowicka 27, \\ 31-510 Cracow, Poland \\ ${ }^{3}$ Institute of Fermentation Technology and Microbiology, Technical University in Łodź, ul. Wolczańska 171/173, Poland
}

In the article by Dorota et al. published in Journal of Microbiology 2014; 52, 169-179. First three authors' first name and last name has been changed. Corrected name is Dorota Zielińska, Danuta Kołożyn-Krajewska, Antoni Goryl. 